KValita Inovácia Prosperita / Quality Innovation Prosperity XIV/1-2 - 201057

\title{
OBSERVANCE AND DEVELOPMENT OF SALIENT QUALITY OVERPRINT FOR TABLECLOTHS EMBROIDERY WITH USE OF RFID TECHNOLOGY
}

\author{
JANA STRAUSZOVÁ, KRISTÍNA ZGODAVOVÁ
}

\section{INTRODUCTION}

Heritage for the Future 'Quality' will be the main topic of $54^{\text {th }}$ EOQ congress in Izmir, Turkey. Tahir Büyükhelvacigil - president of The Standards Turkish Institution in his speech underlined that: "Quality is the best heritage we can pass on to the future generation. Quality is a value that would nbever run its course and that could be enriched through continuous improvement, change and novelties, and in this respects, it bridges the present and the past in the most reliable way. Quality enables each generation to pass on the future generation better living condition".

The property ream for chosen regions of Slovak Republic was in past time a flat stitch by accentuation, filling big ornamental plant, fill whole areas intended for decoration up. The original material was wool, later cotton in red or green (sadness) tones. The embroidering into frame at predraw pattern and estetic embroidery was developed later, also embroidery in seam, bonnets, sails and tablecloths (Liptovské Revúce, 2010). The embroidery at the utility textil and clothes, which were in time of production considered like esthetic element and it has in present time relatively great artistic value for future generation.

Mission of paper is to enable those interested in observance and development quality embroidery typical of the region use with RDIF technologies for designing, implementing and providing overprint for tablecloths embroidery.

\section{SALIENT AND COMPLEXITY ENTITY OF EMBROIDERY}

Quality from basic philosophical perspective can be defined also like summary of entity property manifestativ in surrounding and time their characteristic functions. (Zgodavová et al., 2002). By properties operate one object to another and we understand by functions how operate one object to another in given surrounding and time.

In the field of study programmes 'Quality of Production', 'Quality Management' and 'Quality Engineering' is wider used terminology allowing to study any production i.e. any processes and products (hardware, software, service and 
processed materials), whether in real or virtual form. This fact leads to the use of basic term of scholastics as an entity (Zgodavová, 2010).

Entity are differentiated by salient properties and functions - by quality and explore on them:

- robustness, and gradation of properties and functions - level of quality entity;

- multiplicity, quantity - quantity of entity.

Depth, detail and thoroughness of the research of properties and functions of entities in relation with the depth - detail and thoroughness of knowledge of their internal environment, external environment, calendar and process time leads to a large number of difficulty clear situations and so from saliency of entities come to their complexity and in this article also to the questions of saliency and complexity of embroidery entities for observance their quality as cultural heritage of region (Zgodavová, 2010).

Saliency is rate of conspicuity, speed with which stimuli attracts to attention of our senses and continuously and then penetrate into the consciousness (Salience, 2010) and can be obtained by direct sighting or device measurement.

By the phrase saliency of embroidery entity means generalized knowledge obtained by modelling, measuring and simulating of the developing process, realizations and providing overprint for tablecloths embroidery on the level of individuals, organizations and protected patterns.

In surrounding is the most attracted for our attention which is by common standard different by colour, size, contrast, strength, rarity or rate of movement, that is what somehow capture. For observance and improvement of properties and functions of products are important about which we know, that for prepare targeted interventions. Final quality of the product will be markedly better (Zgodavová, 2010).

Saliency is depending on our senses and we can say about saliency for our hearing, sighting, tactile, taste and scent sensation and their device measurement.

Helping to individuals (as human, also animals) align senses under the importance. The more has individual developed some senses, the more has on detail level known sense saliences. The more is some sense difference from normal - common standard, the more attract and more important. We can say about complexity, respectively detail saliency.

The simplest understanding of complexity is description of properties and functions of entities and their interactions in changing surround in the time. Complexity is currently much frequented term, which is addicted to few research workstations also, magazines, for example: Journal of Complexity. Complexity: Relation and material diversity: geometric, colour, mechanical, electrical, chemic 
also in various combination and forms in common surround and in time coming properties.

\section{STATE OF ART OF PREPARATION, REALIZATION AND PRODUCTON OF OVERPRINT FOR TABLECLOTHS EMBROIDERY}

Overprint for tablecloths embroidery was developed not only in Slovakia, but also in surround countries already several decades ago. Pattern which is overprinted on cloth, whether canvas, currently more used white or beige tesilan, which is later embroidered. This hobby is requested again by people who found it again in countries Austria or Switzerland, where were developed small commercial fabrics for this production and final embroidering.

The first condition before start with digitization is necessary to know preparing, realization and providing of overprint for tablecloths embroidery these days. Because more tasks can be make in duplicate.

Patterns are obtained especially from magazines, whether changing with another, or traced by fences or formers. Paper is necessary grip on base and prevents displacement. This pattern is repainted in thin tracing-paper, which has to be on base of polystyrene over punched by hole punch, or thin needle. Currently this phase of preparation is the most time and human energy consuming. Average length of one pattern production in size $50 \times 50 \mathrm{~cm}$ is approximately $10-15$ hours. The aim of the digitization is to reduce this time aprox.1 hour/whole production and less. It also depends by the machine production rate. In the next step is over punched pattern by technical petrol and blue ultramarine pro-chafe on based cloth 'tesilan'.

Selecting concepts for a historical event ontology (Kuittinen, et al., 2008) is a frequent task in archiving and also for semantic web applications. For example (Sinkkilä, et al 2008), in semantic indexing, concepts describing the item to be indexed must be located from domain ontologies. Many semantic search systems also require the user to create search patterns by picking up concepts and relations to be matched against the instance database.

The purpose of digitization and location of RFID tags on the based pattern is as short as possible to cut down the time of overprint for tablecloth embroidery production and also to observe its quality heritage and improve process of preparation.

For globally digitization is a necessary scanning already existing patterns. Because already scanned data is necessary save on adequate class of 'non-aging' memory medium. 


\section{METHODOLOGY OF PREPARING DIGITIZATION, REALIZATION AND PROVIDING OVERPRINT FOR TABLECLOTHS EMBROIDERY}

Digitization of process preparing, realization and providing overprint for tablecloths embroidery consist in scanning of patterns from magazines, the following „cleaning“ of needless lines, mistakes and errors of image case for example printing of magazine, or paper error etc.

Became a cases when on one page is draw more different overlapping patterns and these are colour different. In this case should be scanned pattern edit by deleting unneeded colour level and then complete all missing places in pattern. By the deleting colour level in pattern create white positions. If this position were crossing two or more lines of patterns, the line in the right pattern stay interrupted and is needed to complete this position. Decisive parameters are:

1) Parameter of scanning space: is given by size of scanning pattern. This can often reached size to format $\mathrm{A} 0$, therefore would be appropriate choose large format scanner to format A0. Also can be used smaller scanner and then individual spaces complete, this variant is deliberate just as side solution, because is very difficult and incorrect.

2) Parameter resolution scanning space: usually given in dpi (dots per inch). It is explaining how many points should be scanned on space of one square inch $\left(2,57 \mathrm{~cm}^{2}\right)$. In case that choose smaller resolution, for example $100 \mathrm{dpi}$, result point will have space $\frac{25,7^{2}}{100}=\frac{660,49}{100}=6,6 \mathrm{~mm}^{2}$.

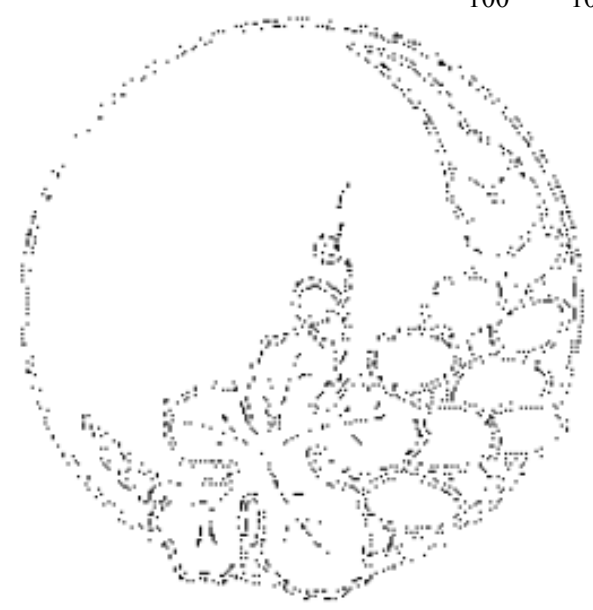

Figure 1 - scanned overprintpattern is scanned in resolution 200 dpi and result page in format $A 4$, size $68 \mathrm{kB}$

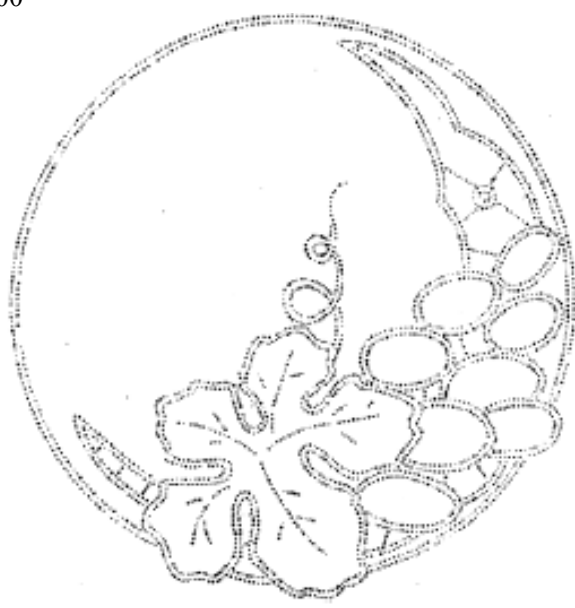

Figure 2 - scanned overprint pattern is scanned in resolution 2400 $d p i$, and the result page in format $A 4$, size 68 MB, then aprox. 1000 times more 
This resolution is deficient for this kind of detailed images. Used is resolution $600 \mathrm{dpi}, 800 \mathrm{dpi}$ and more. Resolution is not depend the size scanning space.

3) Another parameter is possible colour of scanning picture. If there are any patterns in black and white, should suffice black-and-white scanner. Cases, when is on one page more patterns and they are colour different, in this case is multicolour scanner necessary. Of these parameters is resulting backup and storage of scanned pictures. The mentioned file sizes were shown for blackwhite pictures, if there will be progressive number of pages is also progressive scanned file until several GB.

4) Also must be take aspect to hardware, which will realize whole scanning process. Necessary is to select efficient computer with large RAM and fast data transfer device between scanner and computer. Necessary is to prevent scanning in a few minutes and computer data processing in hours.

5) File backup is realized by saving on memory medium as DVD, Blue Ray discs, which providing available capacity $25 \mathrm{~GB}$ in base settlement (one page, single layer), instead 18 GB in maximum use double layer DVD discs in the same memory. DVD is also sufficient medium, from the side of price. In this case one damaged DVD will not be as waste able as damaged Blue Ray discs and also DVD price and memorable memories is much lower. Blue Ray memory devices can record also DVD, or CD discs.

6) Production scanned and archived overprints for tablecloths embroidery is realized by printing on large format plotter. Practically almost all of large format plotters are able also scan, so can obtain two devices in one multi device for whole production. On the base of this chosen parameters hardware should be appropriate fully eliminate phase of over punch tracking-paper by needle as in case of manual production, but patterns place in computer on cloth in required format, which will be printed by plotter and then cut single patterns on cloth (size of one packet of tesilan $-30 \times 1,4 \mathrm{~m}$ ). By this concept can be added one final product as colour parts of pattern, which will be like colour model for embroidery. Colour on cloths has to be washable (by washing), so it will not be problem if there stay any different colours as is the embroidered part. It should be some kind of "colour legend".

\section{PROCESS OF SCANNING AND SAVING ON RFID MEDIAS}

If patterns pass scanning process will be saved in deposit, where allocated by serial number. These numbers will be the same as serial numbers of pattern in database. At the scanned patterns is need to place RFID tags with serial number. For this purpose can be used RFID serial number and set new serial number or combination of two alternatives. The optimal is combination of numbers because patterns are separated to seasonal, yearly-round patterns, Richelieu and crossstitch embroidery. The first could mark the type or seasonality and second part the concrete pattern (for example: 001 - 987654 / 90x90 $\rightarrow$ pattern in Christmas 
section - number of tag and number of pattern/ size - the pattern can have more size which are placed at the another templates).

Scanned items will be deposit in internal database of industrial patterns with added RFID tag accordance to which is possible to indentify and choose by scanner or another device. The device for transfer information must have a reader. This reader will receive, keep and in case of need send them to another process device. For this reason is not necessary to keep all information in the reader permanently in continuously communicate with computer and plotter.

Plotter will print by pattern on cloth. The aim of this stage is speed the production process up and also overall efficiency of production. This method of production can be implemented as well in area of SMEs as in large industrial processing. As well by keeping the patterns will avoid loose and abuse. If there will happened any degradation of database source is possible to renew by RFID serial number (Lahiri, 2006).

\section{FUTURE DEVELOPMENT}

With digitizing of the whole production process, the patterns can be archived on digital media as DVD, Blue Ray Disc and many others as the technology are rapidly improving. By detailed editing of the scanned picture, even the biggest patterns can be saved as small bitmaps (bmp). Using the vector logic there will be enough to save only one file of the same pattern for different dimensions without any lost of quality, which will allow developing new patterns much faster and more flexible according to customer needs.

By preparing of worldwide database of such patterns, there will be the possibility to compare the styles of the patterns from different areas of the world in time, which might be useful for historians to compare 'life style' and its improvement based on living conditions in that area. If such database will be supplemented by mathematic control algorithm, which will count unique control string for each RFID tag (pattern) individually based on pattern structure can ensure, that no pattern was changed and it is unique. Such system can be then used for any database based on pictures, for example archives and many others.

\section{CONCLUSION}

The main aim of this paper was to summarize state of art and procedure of the production and point to possible improvements in this field. By digitizing of the procedure there is possibility to make the whole process more efficient with possibility to place the patterns to the tesilan regarding to required dimension of the pattern. Also to control whole production process by computer technologies, and increase the quality of the patterns with more accurate placed points, even using different colours, which is not unable to be done by hand, but require very accurate handling and repeating of the procedure for several times. Using of 
computer technologies will also release the needle punch process, as there is no need to have the patterns punched anymore.

\section{REFERENCES}

Kuittinen, H., Tuominen, J., Hyvönen, E. (2008), "Extending an ontology by analyzing annotation co-occurrences in a semantic cultural heritage portal", in Proceedings of the ASWC 2008 Workshop on Collective Intelligence (ASWC-CI 2008), $3^{\text {rd }}$ Asian Semantic Web Conference, ASWC, 2008.

Lahiri, S. (2005), RFID Sourcebook, New Jersey(USA) - IBM Press/Pearson Education Company, ISBN 0-13-185137-3.

Liptovské Revúce (2010): Retrieved 2010-09-10, from http://www.sliacky.eu/ work/liptovskerevuce/.

Majerík, M., Hartanský, R., Zgodavová, K. (2010), "Mechatronic Product Interchangeability Management: Electronic Components", in: Annals of DAAAM for 2010 \& Proceedings of the $21^{\text {st }}$ International DAAAM Symposium, pg. 0263, ISBN 978-3-901509-73-5, ISSN 1726-9679, Editor B. Katalinic, Published by DAAAM International, Vienna, Austria 2010.

Salience (2010): Retrieved 2010-09-10, from http://cs.wikipedia.org/ wiki/Salience

Sinkkilä, R., Mäkelä, E., Hyvönen, E. (2008), “Combining context navigation with semantic autocompletion to solve problems in concept selection", in: SEMMA 2008 Workshop, $5^{\text {th }}$ European Semantic Web Conference, ESWC, 2008.

Zgodavová, K. (2010), Štúdia k principom a koncepciám študijných programov v študijnom odbore kvalita produkcie, TnUAD v Trenčíne, ISBN 978-80-8075380-1.

Zgodavová, K. Linczényi, A., Nováková, R., Slimák, I. (2002): Profesionál kvality, TU Košice, 80-7099-669-2.

\section{ABOUT THE AUTHOR}

Jana Strauszová, Mgr., - Ph.D. student of Alexander Dubček Univeristy of Trenčín, e-mail: jana.strausz@gmail.com

Kristína Zgodavová, prof. PhD., - professor at the Alexander Dubček Univeristy of Trenčín, e-mail: zgodavova@tnuni.sk 